\title{
Vascular Proliferation of the Thyroid: Potential Histopathological Pitfalls as a Consequence of Fine Needle Aspiration
}

\author{
Suvi I. Hovi Ivana Kholová \\ Department of Pathology, Fimlab Laboratories, Tampere University Hospital, and Department of Pathology, School \\ of Medicine, Tampere University, Tampere, Finland
}

\section{Keywords}

Thyroid · Neovascularisation · Angiogenesis - Vascular proliferation · Histologic alterations · Fine needle aspiration biopsy $\cdot$ Haemangioma $\cdot$ Angiosarcoma

\section{Abstract}

Objective: Fine needle aspiration biopsy (FNAB) can cause reactive histopathological changes, commonly including haemorrhage and granulation tissue. The literature describing vascular proliferation after FNAB is sparse. We aimed to describe neovascularisation in thyroid gland specimens as a consequence of FNAB. Study Design: We analysed all thyroid histopathological specimens from the Fimlab Laboratories collected between 2010 and 2013 for neovascularisation and distortions in the accompanying tissue. We evaluated HE-stained slides and CD31-, podoplanin-, and Ki-67-immunostained slides. Results: We observed vascular proliferation in 64 out of 787 specimens (8.1\%). In these patients, the mean age was 62 years, 43 were female and 21 were male. Previous FNAB data were available in 49 cases (76.6\%). In 51 cases $(79.7 \%)$, the neovascularisation occupied less than $5 \%$ of the thyroid gland area. The vessel dilatation was moderate in 28 cases (43.8\%) and low in 20 cases (31.3\%). In tumours, neovessels were detected within the tumour and in the surrounding tissue. Conclusions: Post-FNAB tissue samples in-
\end{abstract}

\section{KARGER}

(C) 2017 S. Karger AG, Basel

E-Mail karger@karger.com

www.karger.com/acy clude dilated newly formed vessels, which pathologists should differentiate from rare thyroid vascular tumours. The proposed mechanism is a traumatically induced haemorrhage followed by haematoma and thrombosis that resolves by recanalisation. A knowledge of tissue alteration is needed to avoid misdiagnoses.

(c) 2017 S. Karger AG, Basel

\section{Introduction}

Fine needle aspiration biopsy (FNAB) of the thyroid gland is a well-established, safe, and rapid method for the management of thyroid nodules $[1,2]$. Thyroid FNAB is useful for selecting patients who need surgical treatment $[3,4]$. Clinical complications of FNAB include haematoma formation and acute airway obstruction, which are fortunately uncommon $[5,6]$.

Previous studies have characterised FNAB needle tract-related histopathological changes in various organs, including lymph nodes, salivary glands, parathyroid glands, and breast [7-10]. The most common change is

The preliminary results of this study were presented as a poster at the 38th European Congress of Cytology in Geneva, Switzerland, on 27-30 September, 2014. 
infarction or necrosis [11-13]. Dissemination of malignant cells during FNAB is rare, as was reviewed by Polyzos and Anastasilakis [14].

In 1994, LiVolsi and Merino [15] described worrisome histologic alterations following fine needle aspiration of the thyroid (WHAFFT). Several subsequent studies confirmed their observations [16-19]. Thyroid FNAB-related histopathological changes often include haemorrhage, fibrosis, granulation tissue, and necrosis [15-21]. Necrosis and infarction of the thyroid gland had already been described before the WHAFFT concept, mainly as case reports and case series [22, 23].

Vascular changes as a consequence of FNAB have been infrequently described [15-17, 24, 25]. They include haemangioma-like vascular proliferation, angiosarcomalike proliferation, papillary endothelial hyperplasia, and thrombosis with recanalisation $[16,17,20]$. Notably, thyroid vascular tumours such as haemangioma and angiosarcoma are remarkably rare [26].

The present study aimed at describing the frequency and histopathological characteristics of vascular proliferation in histopathological specimens from the thyroid gland, and its possible relation to previous FNAB. Here, we present a detailed analysis of 64 cases covering a 4-year period.

\section{Materials and Methods}

The study was conducted at the Department of Pathology, Fimlab Laboratories, Tampere University Hospital, and was approved by the local ethical committee. We reviewed all total thyroidectomy and thyroid lobectomy samples obtained between January 2010 and December $2013(n=787)$ for vascular proliferation. The surgical specimens were routinely fixed in $10 \%$ formalin and processed into paraffin blocks. The tumour cases were totally blocked. In goitre cases, all nodules were sampled and there was a minimum

Fig. 1. Histopathological and immunohistochemical characteristics of vascular proliferation. a Dilated thin-walled capillaries surrounded by haemorrhage and cystic degeneration in nodular goitre. HE stain. Original magnification $\times 40$. $\mathbf{b}$ Dilated, mainly bloodfilled capillaries in a fibrin-rich haemorrhagic area in nodular goitre. HE stain. Original magnification $\times 40$. c The case of follicular adenoma: dilated vessels with fibrin-rich walls represent arteriole/venule levels. HE stain. Original magnification $\times 20$. d Area of oedema, haemorrhage, and onion-like fibrin deposits surrounding dilated capillaries in follicular adenoma. HE stain. Original magnification $\times 20$. e Clusters of dilated capillaries in a haemorrhagic area in an oncocytic variant of follicular adenoma. HE stain. Original magnification $\times 40$. $f$ A thrombotic vessel in the vicinity of papillary carcinoma. HE stain. Original magnification $\times 100$. of 3 blocks per lobe. Sections of $4 \mu \mathrm{m}$ were stained with haematoxylin and eosin (HE). We performed additional immunostainings with primary antibodies detecting the endothelium (CD31, dilution 1:400, clone JC70A; DAKO Denmark, Glostrup, Denmark), lymphatic endothelium (podoplanin, dilution 1:200, clone D2-40; DAKO Denmark), and proliferation (Ki-67, clone MIB-1, dilution 1:200; DAKO Denmark). We used a fully automated immunostaining system (Bondmax; Leica Biosystems Newcastle Ltd, Newcastle-upon-Tyne, UK).

Neovascularisation was further analysed for localisation within the thyroid gland, the total area and the dimension of the vessels, as well as endothelial characteristics. Also, we evaluated the presence of haemorrhage, thrombosis, fibrin deposits, oedema, fibrosis, necrosis, granulation tissue, and cystic degeneration in the tissue around the neovessels.

We used IBM SPSS (version 21.0) for statistical analysis. Significant associations were defined using the $\chi^{2}$ test.

\section{Results}

Out of 787 thyroid specimens, vascular proliferation was found in 64 cases $(8.1 \%)$. The study population consisted of 43 females and 21 males aged 21-88 years (mean age 62 years). The histopathological diagnoses were papillary carcinoma in 6 cases, follicular carcinoma in 7 cases, follicular adenoma in 25 cases, and nodular goitre in 26 cases. In addition to these main diagnoses, Hashimoto thyroiditis was diagnosed in 16 cases. Oncocytic metaplasia was found in 28 cases, with oncocytic tumour variants that included oncocytic papillary carcinoma in 3 cases, oncocytic follicular carcinoma in 4 cases, and oncocytic follicular adenoma in 15 cases.

Data on the preceding FNAB date and diagnosis were available in 49 cases $(76.6 \%)$. The frequency of FNAB availability and the distribution of the main diagnoses were comparable between the studied cases and the rest of the department specimens.

g Thick-walled, fibrin-rich, CD31-positive vessels in follicular carcinoma. CD31 immunohistochemistry. Original magnification $\times 40$. $\mathbf{h}$ Numerous irregular venules or arterioles revealed CD31 positivity in nodular goitre. CD31 immunohistochemistry. Original magnification $\times 40$. i Dilated irregular capillaries showed features of branching in another goitre case. CD31 immunohistochemistry. Original magnification $\times 100$. j Irregular thickened walls of newly formed vessels in a goitre case. CD31 immunohistochemistry. Original magnification $\times 200$. k No lymphatic vessels were found in vessel-rich areas. Podoplanin immunohistochemistry. Original magnification $\times 100$. I Proliferation activity as detected with Ki-67 antibody was sparse in newly formed vessels. Ki-67 immunohistochemistry. Original magnification $\times 100$.

(For figure see next page.)
180

Acta Cytologica 2017;61:179-186

DOI: $10.1159 / 000476024$
Hovi/Kholová 
Radiologists performed ultrasound-guided FNABs with $22-\mathrm{G}$ needles. In $40.8 \%$ of the cases, FNAB was taken less than 2 months before surgery, and in total the FNAB time frame ranged from 1 month to 2 years. The dilatation of neovessels correlated with the FNAB time span, but no statistical difference was found for the total vessel area. In 9 cases, FNAB was repeatedly taken twice and in
1 case was taken 3 times. The data were unavailable in 15 cases (23.4\%) because information was not available for FNABs obtained in private clinics or other regions.

The observed vessels were capillaries, venules, and arterioles. The vessel shapes were irregular and dilated, and they were mainly clustered (Fig. 1a-f). The endothelium was positive for pan-endothelial marker CD31 (Fig. 1g-
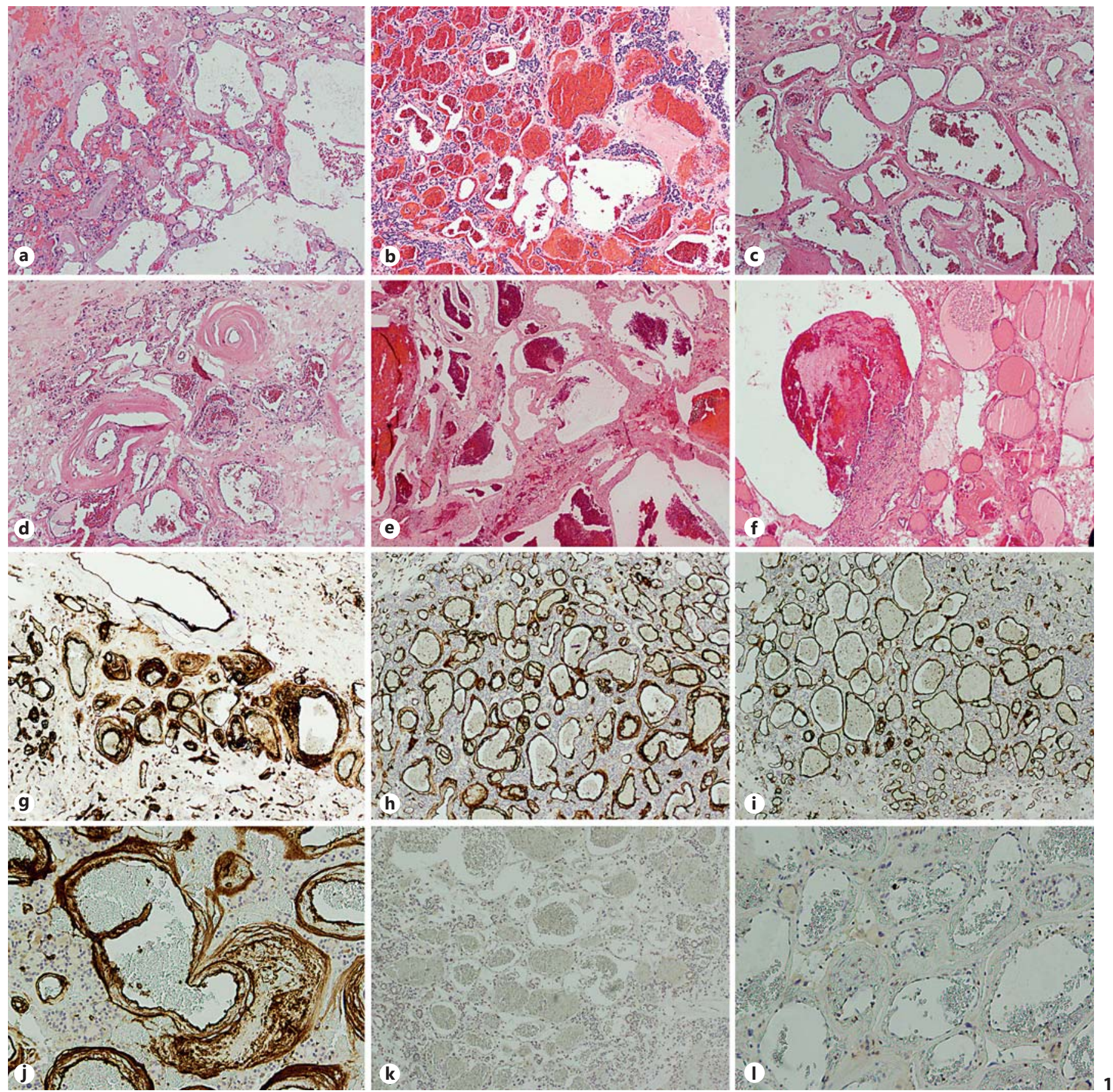

Post-FNAB Thyroid Neovascularisation

Acta Cytologica 2017;61:179-186 


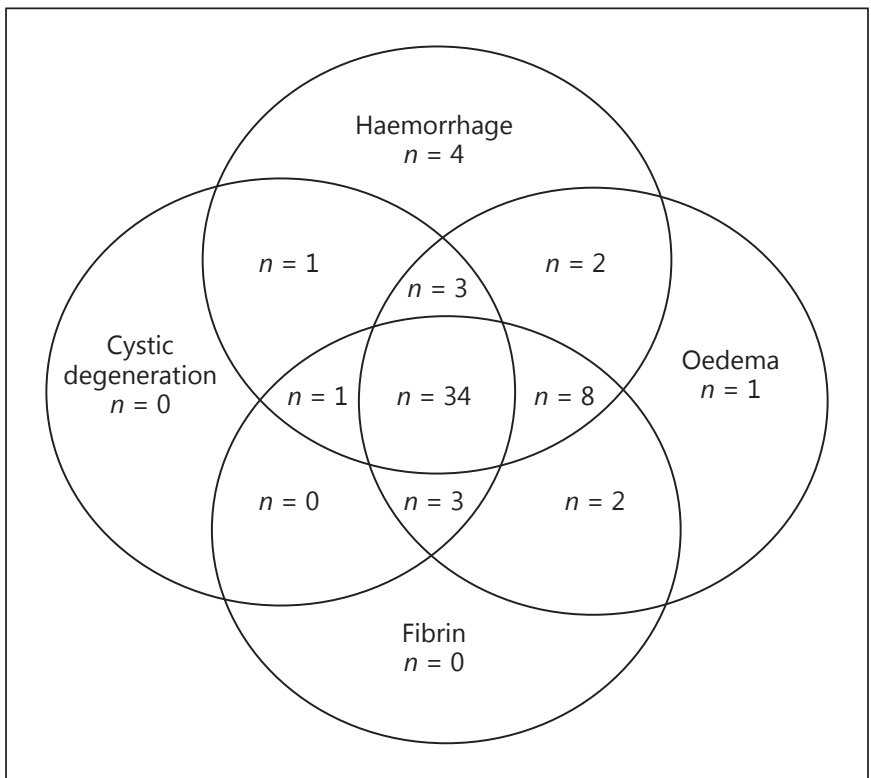

Fig. 2. Co-presence of haemorrhage, oedema, fibrin deposits, and cystic degeneration with vascular proliferation in the presented study.

j), but negative with lymphatic endothelium marker podoplanin (Fig. 1k) [27]. We did not find mitoses or nuclear atypia in the endothelium. No proliferation activity was detected with $\mathrm{Ki}-67$ in the endothelium and the tissue surrounding vascular structures (Fig. 11).

The newly formed vessels were characterised by dilatation, branching, and sprouting with local endothelial irregularities. The neovessel areas varied among the cases. The area reached $80 \%$ of the thyroid gland tissue sections in only 1 case. In 51 cases (79.7\%), the neovascularisation occupied less than $5 \%$ of the thyroid gland area. In all cases without FNAB data, the area was $<5 \%$ and accompanying changes were limited. It is noteworthy that in $34.7 \%$ with FNAB data available, the neovascularised area was $\geq 5 \%(p=0.008)$. According to the main diagnoses, in 21 out of 24 nodular goitres, the area was less than $5 \%$.

We differentiated the vessel dilatation into 3 grades, which were high grade in 16 cases $(25.0 \%)$, moderate grade in 28 cases $(43.8 \%)$, and low grade in 20 cases (31.3\%). The accompanying inflammatory infiltrates of Hashimoto thyroiditis did not influence the vessel characteristics, dilatation, or total area. In fact, the neovessels were not localised in the inflammatory areas.

We found vascular changes within the tumour in $92.0 \%$ of adenomas and $61.5 \%$ of carcinomas $(p<0.001)$.
The surrounding tissue harboured vascular changes less often, but still with remarkable frequency. Similarly, in nodular goitres, we found neovascularisation within the nodules.

In the majority of the cases in which we observed haemorrhage $(90.6 \%)$, oedema $(84.4 \%)$, fibrin deposits (79.7\%), and cystic degeneration (65.6\%), the FNABs were taken less than 2 months before surgery. Figure 2 shows clustering of the changes.

Surprisingly, we found thrombosis only in 4 cases (6.3\%; Fig. 1f) and necrosis in 3 cases (4.7\%). Necrotic lesions did not correspond to areas with oncocytic metaplasia. We observed fibrosis in $32.8 \%$ of the cases.

\section{Discussion}

The thyroid gland is a highly vascularised organ [28]. Vascular endothelial growth factor levels are also high in the thyroid tissue [29]. The diagnostics of thyroid vascular lesions are not straightforward. The heterogeneous disease spectrum consists of reactive lesions like benign endothelial proliferation, benign haemangiomas, and extremely rare malignant angiosarcomas [26]. Table 1 represents a literature review of thyroid haemangiomas. Outside the endemic alpine area, angiosarcomas and malignant haemangioendotheliomas are uncommon [44, 45]. Table 2 summarises various non-tumourous vascular lesions, which are not related to $\mathrm{FNAB}$ [46-49].

Several studies have described the relation of FNAB and vascular proliferation [15-19, 24, 25, 50] (Table 3). In the WHAFFT concept article, however, only dilated vessels were mentioned [15]. Erzös et al. [16] found vascular proliferation and thrombosis in $45 \%$ of thyroids that were aspirated, but they did not find these changes in non-aspirated cases. In contrast, Bolat et al. [18] reported vascular changes in only $2.7 \%$ of studied thyroids. In another series, 10 out of 102 thyroids showed vascular changes, led by thrombosis and recanalisation in 5 cases [17]. It is noteworthy that, in contrast to our data, all the cases of vascular changes were associated with necrosis. Our own necrosis cases were not accompanied by neovascularisation [21].

Interestingly, Pandit and Phulpagar [17] also showed angiosarcoma-like alterations in a specimen 147 days after FNAB. Erzös et al. [16] did not report nuclear pleomorphism and mitotic figures, which is consistent with our results. In some cases, plump endothelial cells and endothelial hyperplasia mimic vascular tumours $[7,26]$. 
Table 1. Thyroid gland haemangiomas

\begin{tabular}{|c|c|c|c|c|c|c|}
\hline First author [Ref.] & Pathological diagnosis & Size, $\mathrm{cm}$ & Sex & $\begin{array}{l}\text { Age, } \\
\text { years }\end{array}$ & $\begin{array}{l}\text { FNA } \\
\text { history }\end{array}$ & $\begin{array}{l}\text { Histologically } \\
\text { verified }\end{array}$ \\
\hline Pickleman [30] & Primary haemangioma/haemangioma NOS & $7.5 \times 3 \times 2$ & M & 56 & No & Yes \\
\hline Pendse [31] & Primary haemangioma & $6 \times 3.5$ & $\mathrm{M}$ & 53 & Yes & Yes \\
\hline Kumar [32] & Primary haemangioma & $4 \times 4$ & $\mathrm{M}$ & 53 & No & Yes \\
\hline Ríos [33] & Cavernous haemangioma & $5 \times 4$ & $\mathrm{~F}$ & 48 & No & Yes \\
\hline Ríos [33] & Cavernous haemangioma & $5 \times 3$ & $\mathrm{~F}$ & 63 & No & Yes \\
\hline Kano [34] & Cavernous haemangioma & $5.5 \times 3.0 \times 2.0$ & $\mathrm{M}$ & 21 & No & Yes \\
\hline Hassan [35] & Epithelioid haemangioendothelioma & $5.0 \times 8.0 \times 4.0$ & $\mathrm{~F}$ & 73 & - & Yes \\
\hline Lee [36] & Cavernous haemangioma & $17.0 \times 16.5$ & $\mathrm{M}$ & 66 & No & Yes \\
\hline Datta [37] & Cavernous haemangioma & $4.9 \times 4.4$ & $\mathrm{M}$ & 25 & No & Yes \\
\hline Ciralik [38] & Cavernous haemangioma & $7 \times 6 \times 6$ & $\mathrm{M}$ & 64 & No & Yes \\
\hline Sakai [39] & Cavernous haemangioma & $5.2 \times 4.8 \times 3.5$ & $\mathrm{~F}$ & 71 & No & Yes \\
\hline Michalopoulos [40] & Cavernous haemangioma & 3.7 & M & 78 & No & Yes \\
\hline Gutzeit [41] & Cavernous haemangioma & 4 & $\mathrm{~F}$ & 84 & No & Yes \\
\hline Maciel [42] & Cavernous haemangioma & $22 \times 21 \times 17$ & $\mathrm{~F}$ & 80 & No & Yes \\
\hline Dasgupta [43] & Cavernous haemangioma & $4.5 \times 4$ & $\mathrm{M}$ & 38 & No & Yes \\
\hline
\end{tabular}

Table 2. Non-tumourous vascular changes not related to FNA

\begin{tabular}{llll}
\hline First author [Ref.] & $\begin{array}{l}\text { Pathological diagnosis of } \\
\text { vascular lesion }\end{array}$ & Cases, $n$ & $\begin{array}{l}\text { Co-existing thyroid } \\
\text { pathology }\end{array}$ \\
\hline Tse [46] & $\begin{array}{l}\text { Capsular intravascular endothelial } \\
\text { hyperplasia }\end{array}$ & 3 & $\begin{array}{l}\text { FNA } \\
\text { history, } \\
(\%)\end{array}$ \\
\hline Schmitz [47] & $\begin{array}{l}\text { Florid capsular carcinoma }(n=2) \\
\text { endothelial proliferation }\end{array}$ & 11 & Poorly differentiated carcinoma \\
\hline Sapino [48] & $\begin{array}{l}\text { Intranodular reactive endothelial } \\
\text { hyperplasia }\end{array}$ & Adenomatous goitre \\
\hline Baloch [49] & $\begin{array}{l}\text { Intravascular Kaposi's-like spindle } \\
\text { cell proliferation }\end{array}$ & 3 & $\begin{array}{l}\text { Follicular carcinoma }(n=3) \\
\text { including oncocytic variant }(n=2)\end{array}$ \\
\hline
\end{tabular}

Due to its high vascularity, the thyroid gland is susceptible to haematoma $[16,24]$. The proposed mechanism of neovascularisation is a needle-induced haemorrhage followed by a haematoma and thrombosis that resolves by recanalisation and vessel formation (Fig. 3). Additionally, Pandit and Phulpagar [17] suggested that, besides vascular proliferation, fibroblastic proliferation is also caused by needle trauma. Traumatisation by palpation and surgery is a less probable explanation [24]. Sapino et al. [48] described spontaneous haemorrhage in long-standing goitre nodules. This observation is in agreement with our results, as FNAB history was negative/unavailable in 15 cases in our series. Sharma and Krishnanand [19] inves- tigated the role of the FNAB technique in the aetiology of vascular proliferation, finding a $21-G$ needle to be less traumatic than other options. The numerous and multiple needle passes increase vascular proliferation development and capsular pseudoinvasion $[15,20]$ that interferes with follicular adenoma versus carcinoma diagnostics. In our personal experience, the neovascularisation did not interfere with the measurements of nodule/tumour size.

In the literature, the needle tract effect after repeated thyroid FNAB has also been described in cytological specimens. In a study by Recavarren et al. [51], 16 cases of Bethesda atypia of undetermined significance (AUS/ FLUS) in repeated FNAB were found. They revealed 2 
Table 3. Vascular proliferation after thyroid FNAB: review of the literature

\begin{tabular}{lclllll}
\hline First author [Ref.] & $\begin{array}{l}\text { All } \\
\text { cases, } n\end{array}$ & $\begin{array}{l}\text { Total vascular } \\
\text { change cases, } n(\%)\end{array}$ & $\begin{array}{l}\text { Vascular } \\
\text { proliferation, } n(\%)\end{array}$ & $\begin{array}{l}\text { Vascular } \\
\text { thrombosis, } n(\%)\end{array}$ & $\begin{array}{l}\text { Papillary endothelial } \\
\text { hyperplasia, } n(\%)\end{array}$ & $\begin{array}{l}\text { Plump endothelial } \\
\text { cells, } n(\%)\end{array}$ \\
\hline Ersöz [16] & 20 & $9(45)$ & $9(45)^{\mathrm{a}}$ & $9(45)^{\mathrm{a}}$ & n.d. & n.d. \\
Pandit [17] & 265 & $10(3.8)$ & $2(0.7)$ & $5(4.9)$ & $3(2.9)$ & n.d. \\
Tsang [24] & 2 & $2(100)$ & $2(100)$ & $2(100)$ & $2(100)$ & $2(100)$ \\
Sharma [19] & 100 & $23(23)$ & $4(4)$ & $20(20)$ & $4(4)$ & $1(1)$ \\
Bolat [18] & 150 & $14(9)$ & $4(2.7)$ & $10(6.7)$ & n.d. & n.d. \\
Ramraje [50] & 2 & $2(100)$ & $1(50)$ & 0 & $1(50)$ & $1(50)$ \\
Baloch [25] & 250 & n.d. & n.d. & n.d. & n.d. & n.d. \\
LiVolsi [15] & 300 & n.d. & n.d. & n.d. & n.d. & n.d. \\
\hline
\end{tabular}

n.d., not determined. ${ }^{\text {a }}$ Reported as vascular proliferation and/or vascular thrombosis.

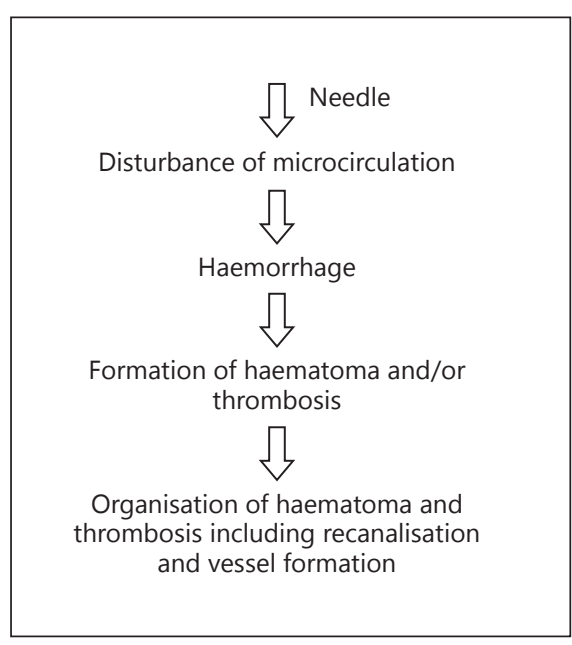

Fig. 3. Mechanism of vascular proliferation development.

samples with atypical stromal, endothelial, and follicular cells embedded in blood or blood clots, probably induced by previous FNABs. In our opinion, the revision of previous slides is necessary to avoid diagnostic inaccuracies. The cases may nevertheless be categorised into the AUS/ FLUS heterogeneous group [52].

Core-needle biopsy (CNB) provides an alternative diagnostic method in non-diagnostic and AUS/FLUS cases [53]. However, thyroid CNB is not widely used in clinical practice. The most common clinical complication is haematoma formation $[54,55]$. We suspect that the CNB procedure can cause similar and even worse histopathological alterations than the FNAB procedure.

In conclusion, post-FNAB changes are often accompanied by dilated newly formed vessels. Proper histopath- ological diagnostics requires the knowledge of reactive post-FNAB tissue alterations and patient history of FNAB in order to avoid misdiagnosis. Pathologists should differentiate reactive vascular changes from rare thyroid vascular tumours. In the clinical practice, a differential diagnosis with angiosarcoma is of paramount importance. However, a secondary haemangioma caused by the organisation of a haematoma is almost impossible to distinguish from a real haemangioma [26]. Nevertheless, the phenomenon of neovessels is quite rare in thyroid gland specimens.

\section{Acknowledgements}

Statistical advice from Anna-Maija Koivisto of the University of Tampere is acknowledged. Research grants of Pirkanmaa Hospital District and Emil Aaltonen Foundation supported this study.

\section{Ethics Statement}

The study was approved by Tampere University Hospital Ethical Committee and informed consent from each individual was not requested. The handling of the tissue blocks/slides was approved by the Finnish Medical Authority Organisation Valvira.

\section{Disclosure Statement}

The authors have no conflicts of interest to declare.
Hovi/Kholová 


\section{References}

1 Cibas ES, Alexander EK, Benson CB, de Agustín PP, Doherty GM, Faquin WC, Middleton WD, Miller T, Raab SS, White ML, Mandel SJ: Indications for thyroid FNA and pre-FNA requirements: a synopsis of the $\mathrm{Na}-$ tional Cancer Institute Thyroid Fine-Needle Aspiration State of the Science Conference. Diagn Cytopathol 2008;36:390-399.

2 Pitman MB, Abele J, Ali SZ, Duick D, Elsheikh TM, Jeffrey RB, Powers CN, Randolph G, Renshaw A, Scoutt L: Techniques for thyroid FNA: a synopsis of the National Cancer Institute Thyroid Fine-Needle Aspiration State of the Science Conference. Diagn Cytopathol 2008;36:407-424.

3 Ko HM, Jhu IK, Yang SH, Lee JH, Nam JH, Juhng SW, Choi C: Clinicopathologic analysis of fine needle aspiration cytology of the thyroid: a review of 1,613 cases and correlation with histopathologic diagnoses. Acta Cytol 2003;47:727-732.

4 Cáp J, Ryska A, Rehorková P, Hovorková E, Kerekes Z, Pohnetalová D: Sensitivity and specificity of the fine needle aspiration biopsy of the thyroid: clinical point of view. Clin Endocrinol 1999;51:509-515.

5 Polyzos SA, Anastasilakis AD: Clinical complications following thyroid fine-needle biopsy: a systematic review. Clin Endocrinol 2009; 71:157-165.

6 Donatini G, Masoni T: Is fine-needle aspiration cytology for thyroid nodules a routine and safe procedure? A series of emergency cervicotomies following FNAC. Langenbecks Arch Surg 2010;395:873-876.

7 Tsang WY, Chan JK: Spectrum of morphologic changes in lymph nodes attributable to fine needle aspiration. Hum Pathol 1992;23: 562-565.

8 Di Palma S, Simpson RH, Skálová A, Michal M: Metaplastic (infarcted) Warthin's tumour of the parotid gland: a possible consequence of fine needle aspiration biopsy. Histopathology 1999;35:432-438.

9 Norman J, Politz D, Browarsky I: Diagnostic aspiration of parathyroid adenomas causes severe fibrosis complicating surgery and final histologic diagnosis. Thyroid 2007;17:12511255.

10 Youngson BJ, Cranor M, Rosen PP: Epithelial displacement in surgical breast specimens following needling procedures. Am J Surg Pathol 1994;18:896-903.

11 Pinto RG, Couto F, Mandreker S: Infarction after fine needle aspiration: a report of four cases. Acta Cytol 1996;40:739-741.

12 Bayramoğlu H, Düzcan E, Akbulut M, Topuz B: Infarction after fine needle aspiration biopsy of pleomorphic adenoma of the parotid gland. Acta Cytol 2001;45:1008-1010.

13 Kern SB: Necrosis of a Warthin's tumor following fine needle aspiration. Acta Cytol 1988;32:207-208.
14 Polyzos SA, Anastasilakis AD: A systematic review of cases reporting needle tract seeding following thyroid fine needle biopsy. World J Surg 2010;34:844-851.

15 LiVolsi VA, Merino MJ: Worrisome histologic alterations following fine-needle aspiration of the thyroid (WHAFFT). Pathol Annu 1994; 29:99-120.

16 Ersöz C, Soylu L, Erkoçak EU, Tetiker T, Gümürdülü D: Histologic alterations in the thyroid gland after fine-needle aspiration. Diagn Cytopathol 1997;16:230-232.

17 Pandit AA, Phulpagar MD: Worrisome histologic alterations following fine needle aspiration of the thyroid. Acta Cytol 2001;45:173179.

18 Bolat F, Kayaselcuk F, Nursal TZ, Reyhan M, Bal N, Yildirim S, Tuncer I: Histopathological changes in thyroid tissue after fine needle aspiration biopsy. Pathol Res Pract 2007;203: 641-645.

19 Sharma C, Krishnanand G: Histologic analysis and comparison of techniques in fine needle aspiration-induced alterations in thyroid. Acta Cytol 2008;52:56-64.

20 Polyzos SA, Patsiaoura K, Zachou K: Histological alterations following thyroid fine needle biopsy: a systematic review. Diagn Cytopathol 2009;37:455-465.

21 Kholová I: Vanishing thyroid gland tumors: infarction as consequence of FNA? Diagn Cytopathol 2016;44:568-573.

22 Jones JD, Pittman DL, Sanders LR: Necrosis of thyroid nodules after fine needle aspiration. Acta Cytol 1985;29:29-32.

23 Layfield LJ, Lones MA: Necrosis in thyroid nodules after fine needle aspiration biopsy: report of two cases. Acta Cytol 1991;35:427430.

24 Tsang K, Duggan MA: Vascular proliferation of the thyroid: a complication of fine-needle aspiration. Arch Pathol Lab Med 1992;116: 1040-1042.

25 Baloch ZW, LiVolsi VA: Post fine-needle aspiration histologic alterations of thyroid revisited. Am J Clin Pathol 1999;112:311-316.

26 Papotti M, Arrondini M, Tavaglione V, Veltri A, Volante M: Diagnostic controversies in vascular proliferations of the thyroid gland. Endocr Pathol 2008;19:175-183.

27 Adamczyk LA, Gordon K, Kholová I, MeijerJorna LB, Telinius N, Gallagher PJ, van der Wal AC, Baandrup U: Lymph vessels: the forgotten second circulation in health and disease. Virchows Arch 2016;469:3-17.

28 Hakala T, Sand J, Kellokumpu-Lehtinen PL, Huhtala H, Leinonen R, Kholová I: Recurrent thyroid cancers have more peritumoural lymphatic vasculature than nonrecurrent thyroid cancers. Eur J Clin Invest 2014;44:825-832.

29 Pikner R, Ludvíková M, Ryska A, Kholová I, Holubec L Jr, Topolcan O, Pecen L, Fínek J: TPS, thymidine kinase, VEGF and endostatin in cytosol of thyroid tissue samples. Anticancer Res 2005;25:1517-1522.
30 Pickleman JR, Lee JF, Straus FH 2nd, Paloyan E: Thyroid hemangioma. Am J Surg 1975;129: 331-333.

31 Pendse AK, Porwal KK: Solitary primary haemangioma of thyroid. J Indian Med Assoc 1998;96:190.

32 Kumar R, Gupta R, Khullar S, Dasan B, Malhotra A: Thyroid hemangioma: a case report with a review of the literature. Clin Nucl Med 2000;25:769-771.

33 Ríos A, Rodríguez JM, Martínez E, Parrilla P: Cavernous hemangioma of the thyroid. Thyroid 2001;11:279-280.

34 Kano M, Kameyama K, Hosoda Y, Sugino K, Ito $\mathrm{K}$ : A cavernous haemangioma of the thyroid gland. J Laryngol Otol 2005;119:828830.

35 Hassan I, Barth P, Celik I, Hoffmann S, Langer P, Ramaswamy A, Wagner HJ, Rothmund $\mathrm{M}$, Zielke A: An authentic malignant epithelioid hemangioendothelioma of the thyroid: a case report and review of the literature. Thyroid 2005; 15:1377-1381.

36 Lee J, Yun JS, Nam KH, Chung WY, Park CS: Huge cavernous hemangioma of the thyroid gland. Thyroid 2007;17:375-376.

37 Datta R, Venkatesh MD, Nilakantan A, Joseph B: Primary cavernous hemangioma of thyroid gland. J Postgrad Med 2008;54:147148.

38 Ciralik H, Citil R, Bulbuloglu E, Bakaris S: A patient with a neck mass. Neth J Med 2008;66: 38-39.

39 Sakai A., Sugitani I, Yamamoto N, Kawabata K: Hemangioma of the thyroid. Clin Med Ear Nose Throat 2009;2:7-11.

40 Michalopoulos NV, Markogiannakis H, Kekis PB, Papadima A, Lagoudianakis E, Manouras A: Primary cavernous hemangioma of the thyroid gland. South Med J 2010;103:674675.

41 Gutzeit A, Stuckmann G, Tosoni I, Erdin D, Binkert CA: A cavernous hemangioma of the thyroid gland: first documentation by ultrasound of a rare pathology. J Clin Ultrasound 2011;39:172-174.

42 Maciel LM, Gomes PM, Magalhães PK, Mello Filho FV, Conti-Freitas LC: A giant primary hemangioma of the thyroid gland. J Clin Endocrinol Metab 2011;96:1623-1624.

43 Dasgupta A, Teerthanath S, Jayakumar M, Hs K, Raju M: Primary cavernous haemangioma of the thyroid - a case report. J Clin Diagn Res 2014;8:151-152.

44 Ryska A, Ludvíková M, Szépe P, Böör A: Epithelioid haemangiosarcoma of the thyroid gland: report of six cases from a non-Alpine region. Histopathology 2004;44:40-46.

45 Tötsch M, Dobler G, Feichtinger H, Sandbichler P, Ladurner D, Schmid KW: Malignant hemangioendothelioma of the thyroid. Its immunohistochemical discrimination from undifferentiated thyroid carcinoma. Am J Surg Pathol 1990;14:69-74. 
46 Tse LL, Chan I, Chan JK: Capsular intravascular endothelial hyperplasia: a peculiar form of vasoproliferative lesion associated with thyroid carcinoma. Histopathology 2001;39: 463-468.

47 Schmitz BA, Singh C, Gulbahce HE, Manivel JC, Pambuccian SE: Florid capsular and pericapsular papillary endothelial proliferation associated with poorly differentiated thyroid carcinoma. Int J Surg Pathol 2011;19:110112.

48 Sapino A, Papotti M, Macrì L, Satolli MA, Bussolati G: Intranodular reactive endothelial hyperplasia in adenomatous goitre. Histopathology 1995;26:457-462.
49 Baloch ZW, LiVolsi VA: Intravascular Kaposi's-like spindle cell proliferation of the capsular vessels of follicular-derived thyroid carcinomas. Mod Pathol 1998;11:995-998.

50 Ramraje SN, Kambale TJ: Fine needle aspiration-induced vascular proliferation of the thyroid: a report of two cases. Cytojournal 2012;9:25.

51 Recavarren RA, Houser PM, Yang J: Potential pitfalls of needle tract effects on repeat thyroid fine-needle aspiration. Cancer Cytopathol 2013;121:155-161.

52 Kholová I, Ludvíková M: Thyroid atypia of undetermined significance or follicular lesion of undetermined significance: an indispensable Bethesda 2010 diagnostic category or waste garbage? Acta Cytol 2014;58:319-329.
53 Hakala T, Kholová I, Sand J, Saaristo R, Kellokumpu-Lehtinen P: A core needle biopsy provides more malignancy-specific results than fine-needle aspiration biopsy in thyroid nodules suspicious for malignancy. J Clin Pathol 2013;66:1046-1050.

54 Karstrup S, Balslev E, Juul N, Eskildsen PC, Baumbach L: US-guided fine needle aspiration versus coarse needle biopsy of thyroid nodules. Eur J Ultrasound 2001;13:1-5.

55 Renshaw AA, Pinnar N: Comparison of thyroid fine-needle aspiration and core needle biopsy. Am J Clin Pathol 2007;128:370-374. 